Send your letters to the editor, British Dental Journal, 64 Wimpole Street, London W1G 8YS E-mail bdj@bda.org

Priority will be given to letters less than 500 words long. Authors must sign the letter, which may be edited for reasons of space-

\section{Ancient homo sapiens}

Sir, I wonder if other colleagues were wary of the statement by 'scientists' that coarse food would have required more chewing and higher bite forces, which could have stimulated growth of the jaw bone and therefore created more room for the wisdom teeth to erupt (the Magdalenian girl BDJ 2006; 200: 311).

Is there any evidence that mandibles increase in length due to chewing coarse food? Arthur Koestler once wrote he could recognise Americans as there was something square about their jaws due to constantly chewing gum but I don't think this interesting observation has ever been proven.

I can accept that a coarse diet may flatten the contact areas and therefore allow a bit more space for lower wisdom tooth eruption, but I suspect that the lack of specimens of ancient homo sapiens with wisdom tooth impaction is more likely to be due to genetics rather than environment. Perhaps we simply haven't collected enough material.

In any event the radiograph clearly shows a lack of root development of the wisdom tooth and the presence of bone distal to the second molar. It doesn't look impacted to me, just unerupted. I'd go for the younger age.

\section{B. D. Skinner}

Muswell Hill

doi: 10.1038/sj.bdj.4813683

\section{Ethical opinions}

Sir, I read Dr Fleming's letter ( $B D J$ 2006; 200: 303) with interest and I have considerable sympathy regarding the 'ethical dilemma' surrounding the often lengthy regulatory review of clinical research.

The ethical review element of research proposals has changed considerably over the last few years, primarily with the development of a single, national application form that, as Dr Fleming observes, may not always seem to be appropriate to all levels of clinical research. From the ethics viewpoint, however, it would be inappropriate to have an application form that is specific to dental research which represents only a small proportion of the workload of Research Ethics Committees (REC). The same argument could be raised by researchers in many other fields and one of the changes that has in fact helped to facilitate ethical review has been the introduction of the single form. This form will, however, continue to be developed and modified so that sections inappropriate to a specific type of proposal are disabled: this of course not only saves time for the researchers but also for the ethics reviewers who have to read all the documents in detail.

In recent years, one of the most challenging ethical dilemmas has been the justification of using a placebo in trials involving patients undergoing third molar extractions and, indeed, there are many other designs of dental trials that raise significant ethical problems, for example: issues surrounding consent; the recruitment of minors; and the storage of tissue, DNA or even clinical data in the long term. The strength of any argument directed towards facilitating the review process further must focus entirely on the level of risk and not the perception that 'these are only teeth' or for that matter, 'gums'!

I do, therefore, accept fully the point that there are clinical trials (both dental and non-dental) that carry minimal, if any, risk to participants (or indeed researchers, sponsors or funders) and the Ad Hoc Advisory Group (Warner) report on the NHS REC system has recently recommended a more proportionate system of review to take account of the level of risk involved. The implementation plan developed by the Central Office of Research Ethics Committees (COREC) has already been published and endorsed by Ministers. One of the most farreaching and significant proposals is the introduction of local and national
Research Ethics Advisors who would have authority to provide a favourable ethics opinion in cases where research involves only minimal ethical issues. Once the ethics community has managed to define the meaning of the word 'minimal', I envisage that such a triage system will have a significant impact in reducing the time required for RECs to provide ethical opinions which, incidentally, they are currently legally obliged to do within 60 calendar days (excluding the time when further information is being sought from the applicant).

\section{P. Heasman}

By email doi: 10.1038/sj.bdj.4813684

\section{Poor practice}

Sir, I assume that most readers will have seen the recent Department of Health public information leaflet What you need to know about changes to NHS dentistry in England: ${ }^{1}$ Is it just me or has anyone else spotted a mistake (or should I say mistakes) in the pictures that appear on this leaflet? I'm afraid there are no prizes for guessing what they are, so please don't be tempted to send your answers on a postcard! In any case, I've listed them here.

First of all, in the large picture on the front cover, the dentist is wearing a wristwatch and what appears to be a ring with a stone, in spite of recommendations for 'rings and watches to be removed during clinical sessions.' 2

In the same picture, the dentist is seen to be using a three in one air/water syringe but the patient is not wearing protective spectacles: this again goes against recommendations for 'patients' eyes to always be protected against foreign bodies or splatter.2

Finally, one of the smaller pictures on the front cover features a dentist taking an intra-oral radiograph. Although it's obvious that a film holder is being used, there is a notable lack of any definitive beam-aiming device (barring the possibility that it's to be fitted on later). 
Guidelines for dental practitioners on the safe use of $\mathrm{x}$-ray equipment ${ }^{3}$ recommend the use of rectangular collimation for bitewings and periapicals and if it is being used, a beam-aiming device is essential to ensure accurate alignment with the intraoral film. Therefore, should we assume that rectangular collimation is not being used in this instance or is the operator just really good at taking $\mathrm{x}$-rays?

To be fair, the points noted are relatively minor (some may even call it nit-picking!) and I can also appreciate that this leaflet has been produced for members of the public who are very unlikely to be aware of the sorts of issues raised. Nevertheless, cross-infection control and radiography/ radiation protection are key elements of clinical dental practice, as illustrated by the GDC's recent consultation exercise on plans to include both of these as compulsory core subject areas in the verifiable CPD requirement. ${ }^{4}$ Therefore, under the circumstances, it would only have seemed right for the Department of Health to be seen to be promoting good practice, unless of course the mistakes were left in deliberately to see if anyone would notice (I doubt it!).

A. Raja

Birmingham

1. What you need to know about changes to NHS dentistry in England. London: Department of Health, February 2006

2. Infection Control in Dentistry: BDA Advice Sheet A12 BDA. February 2003.

3. Guidance Notes for Dental Practitioners on the Safe Use of X-Ray Equipment: NRPB. Department of Health. June 2001.

4. A Step Towards Revalidation - GDC Consultation Paper. March 2006. http://www.gdc-uk.org/ News+publications+and+events/Consultations/ Current+consultations/Revalidation+consultation.htm

doi: 10.1038/sj.bdj.4813685

\section{Young dentists and the new contract}

Sir, I am writing as a Senior House Officer and on behalf of my colleagues. The current change in 'PDS' or new 'contract' has not affected me as much as my colleagues in general dental practice. My time in the hospital has made me less aware of the intricacies of the changes that are going to take place.

Most of my colleagues as young hospital dentists will go back into general dental practice. Our main concern is how the 'new contract' will affect hospital dental practitioners going back into practice. There are many SHO posts in the UK, and this would affect quite a large number of young dentists.

Putting it simply, the 'new contract' will introduce contract negotiations of the principal dental practitioner with the primary care trust (PCT). These contract negotiations are dependent on the catchment area and services that the practice can provide. With the extra experience gained (which in most cases will be oral surgery) and postgraduate qualifications (MFDS.RCS), how would this affect the negotiations?

In addition, another question which arises is how the new contract will affect the excellent vocational training available in the United Kingdom. How will the PCT contract affect the new Vocational Dental Practitioner and progression to 'associate', and how will the funding be provided for vocational training?

I would be grateful for you opinion and insight.

I. Shargill

Birmingham

Linda Wallace, Director of BDA

Professional Services responds: In the new world of NHS general dental practice, it is true that finding a job as an associate, whether on leaving VT or a hospital post, will not be quite as simple as it was before. Applicants will need to find a post in a practice which has contract value and the corresponding 'units of dental activity' available, either because an associate has left, and the PCT is willing to leave the activity with the practice, or because the practice has managed to negotiate more contract value with the PCT. Dentists will follow the money in future, rather than the money following the dentist. It is too early to say how difficult it will be in practice, however. PCTs may wish to buy specialist services if they are available, and in doing so will be following the guidance relating to 'dentists with special interests'.

$V T$ money is specifically allocated to $V T$ and PCTs and Deans will be deciding where the posts should be. Selection of practices as training practices will take account of service need. It will not be possible for VDPs to stay on in the same practice unless an associate leaves or additional contract value is available. doi: 10.1038/sj.bdj.4813686

\section{Cartridge size}

Sir, the recent worldwide shortage in dental local anaesthetic cartridges has prompted me to raise the question of our $2.2 \mathrm{ml}$ local anaesthetic cartridges sup plied to the UK market.

Can anybody give me one good scientific reason why we should use $2.2 \mathrm{ml}$ local anaesthetic cartridges compared to $1.7 \mathrm{ml}$ cartridges that are used throughout the rest of the world? Surely it is our duty as clinicians, when injecting any type of drug into our patients, to administer the minimum amount of drug that will achieve the desired outcome? $1.7 \mathrm{ml}$ of local anaesthetic solution is very effective in achieving adequate levels of anaesthesia for our dental procedures. Why therefore, do we persist in giving 2.2 $\mathrm{ml}$ of local anaesthetic in the UK? Perhaps it is nothing more than, traditionally, our dental local anaesthetic syringes have accepted the larger size cartridge.

Surely, the present crisis in local anaesthetic manufacturing worldwide, should prompt us to dispense, once and for all, with $2.2 \mathrm{ml}$ cartridges and fall in line with the rest of the world and use the $1.7 \mathrm{ml}$ cartridge size?

N. Foot

Newbury

doi: 10.1038/sj.bdj.4813687

\section{Bunch of simpletons}

Sir, I hope that no dental person outside the UK reads N. Cole's letter (BDJ 2006 200: 361) regarding the use of the title doctor and mission statements, which I believe to be a parody of the truth, and tries to brand us all as a bunch of simpletons. I believe the reason for adopting the title of doctor was to bring us into line with the whole of the western hemisphere, and there were other perfectly valid reasons.

I do not believe that Richard Branson became one of the most admired and successful business men in modern times by 'fussing' about management, marketing etc. If $\mathrm{N}$. Cole feels that he needs a 'mission statement' to solve his problems he should attend any of the well established practice management courses to learn how to set himself in the proper direction with the right ideas in his head.

The expression 'We try to fix it as cheaply as possible' are words that he is frightened he might have to attribute to us. Where do they come from? Perhaps he saw them in a dream, carved in stone over the front entrance of the DoH.

\section{B. Posner}

By email

doi: 10.1038/sj.bdj.4813688

\section{Financial incentives}

Sir, I was amused reading the strongly worded letter by N. Ali and colleagues, criticising the study by Macluskey. The study may have been flawed, but the criticism of the surgical dentistry practice in carrying out more sedation, because of 'an additional fee being payable' should be honestly faced by all, especially the authors of the letter.

Having worked in general dental practice in various parts of the country, and having referred patients with PMI (private medical insurance) to 'practitioners of oral and maxillofacial 
surgery', the authors of the letter will already be familiar with the role financial incentives have to play.

As in the surgical dentistry practice, a lack of discrimination means that all my PMI patients referred to a consultant for dento-alveolar opinion have been submitted for surgery. Secondly, patients with PMI almost always have a general anaesthetic. Can the number of private patients with PMI having general anaesthetia be justified? Are such practices subject to "peer review or continuous peer scrutiny'? It would be interesting to hear from GDPs if any private patients are routinely refused surgery, or have treatment under LA.

Those of us who work in general practice are aware of the financial incentives that can influence treatment options. To believe that a surgical dentistry practice, or 'practitioners of oral and maxillofacial surgery', should be any different is demonstrably not true.

R. Willett

Lechlade

doi: 10.1038/sj.bdj.4813689

\section{Time-travelling dentist}

Sir, what year would you want to go back to if Dr Who offered you a ride in his Tardis? For me, it would have to be 1966. Why 1966? Well, first of all I could catch up with and warn myself not to eat my grandma's Everton Mints; second I could see England win the World Cup and third I could see for myself what caries looked like in the pre-fluoride toothpaste era!

Now, 40 years later I am a salaried dentist treating children in North Lincolnshire. I am reading with special interest the series of articles on the 2003 Child Dental Health Survey ${ }^{1}$ especially as I had contributed to it in the role of an examiner. The survey was organised with great precision. The training and calibration week held in the Midlands was a very enjoyable experience after which I returned to North Lincolnshire to collect the data. I was duly dispatched to four nice schools in the better part of town, and collected my data which included lots of plaque, gingivitis, erosion, a bit of trauma but very little caries! How fantastic, what a wonderful job we are doing as a profession and how I agree with the sentiments of C. Dugmore, ${ }^{2}$ when he asked 'Where has all the caries gone?'

I will tell you where it has gone, it is still there, and no, I don't need a Tardis or a DeLorean. Having collected my superb data that would make Mr Blair a very happy man, I returned to my post-war clinic in the poor part of town where it could almost be 1966 again. You see, I treat the tail of the caries distribution in an area where there is no access to NHS General Dental Services for patients in search of a dentist. At least the children in the town can get treatment in our very small service. My appointment book does not have a space for two months, we can't turn anyone away and young children with multiple pulpally involved teeth seem to be more the norm than the exception. That is the reality, but unlike 1966, children have to wait two months for paediatric extractions with general anaesthetic! Have there really been improvements Mr Blair? I feel that children with high dental needs have been ignored for too long. There is nothing in the new GDS contract that will encourage dentists to risk accepting these children as new patients! Will there be more money from the PCTs for the salaried services to expand and pick up the pieces?

So there we are, 2006, hopefully the year England wins the World Cup, just like 1966. Not only will we have the best footballers in the world, we have the knowledge that 12-year-olds from the UK have the best dental health in Europe. I am afraid I can't get too excited about the latter! Prompt treatment of children in pain or reduced mean DMFT, what is more important?

\section{A. Denton}

Doncaster

1. Pitts N B, Chestnutt I G, Evans D et al. The dentinal caries experience of children in the United Kingdom 2003. Br Dent J 2006; 200: 313-320.

2. Dugmore C. Where has all the caries gone? Br Dent $J$ 2006; 200: 421

doi: 10.1038/sj.bdj.4813690

\section{Beneficial beverages}

Sir, I read with some interest in the article $A$ survey of oral and maxillofacial pathology specimens (BDJ 2006; 200: 447-450) that gin (or other clear alcoholic beverage ) may be used to fix a biopsy specimen.

I now wonder if the number of biopsies will increase along with the sale of gin or vodka as now we can claim tax relief for its use as a surgery consumable.

I have often thought it would be beneficial to keep such clear alcoholic beverages in the surgery!

A. Stubley

Polesworth

doi: 10.1038/sj.bdj.4813691

\section{Burnout syndrome}

Sir, I found the recent paper by Newton et $a l .{ }^{1}$ to be very interesting and a welcome assessment of the need for further research into the various stressors affecting dentists and dental care professionals. However, the statement, 'General dental practitioners have a higher risk of suicide than the general population' is not supported by the available evidence, as documented by Alexander, ${ }^{2}$ in his excellent literature review of the subject, published in 2001, nor by any further statistically significant evidence I have been able to find. It appears that a 1933 study, which I have been unable to locate, looked at the suicide rates between various workers, including dentists, lawyers and doctors and concluded that this group was at a much higher risk than other white collar workers. In the 1960s, the findings of this study were further promulgated and the myth of higher dentists' suicide rates continued.

However, even if there is no significant difference in suicide rates between dentists and the general population, there is a great need for research into the causes, prevention and treatment options for dentists and DCPs of factors leading to increased stress and eventually, professional burnout syndrome. Since professional burnout syndrome may ultimately lead to suicidal intent or even an event, it is important to recognise and prevent this. Along the way the dentist or DCP may develop a psychological mood disorder, dysthymia, as discussed by Frey ${ }^{3}$ in his paper, which is a chronic, prolonged disease and difficult to diagnose, as it is less severe than the major depressive illnesses.

At least, as a profession, we should discuss these issues - in the same way that substance abuse is now openly discussed - and put together the resources for data collection and analysis of the stress related problems affecting the dental team. Perhaps we have also been a little blinkered, as frequently happens in dentistry, so rather than just concentrating on our own field, and that of medicine in general, we could look to other professions and groups of workers, whom we may find to be under greater stress than we are, and examine how they identify and treat these stressors.

\section{T. M. Johnson}

York

1. Newton J T, Allen C D, Coates J, Prior J. How to reduce the stress of general dental practice: the need for research into the effectiveness of multifaceted interventions. Br Dent J 2006: 200:437-440.

2. Alexander R E. Stress-related suicide by dentists and other health care workers. Fact or folklore? JADA 2001; 132: 786-794.

3. Frey R. When professional burnout syndrome leads to dysthymia. J Can Dent Assoc 2000; 66: 33-34.

doi: 10.1038/sj.bdj.4813692

\section{The wide gulf}

Sir, in an otherwise erudite research summary, Peter Crawford suggested that the paper Preformed metal crowns for carious primary molars, by Innes 
et al., ${ }^{1}$ would become a landmark in the restorative care for children. I beg to differ. It should be pointed out that this is a retrospective study based on uncontrolled general dental practice records, and therefore not the sort of study that could be considered for evidence, based dentistry. Of greater importance, though, is the effect of this approach on oral care in children.

Undoubtedly, treating children can be challenging, even for specialists, and the promise of an easy solution to the difficulties must be very attractive to a harassed dentist. Historically, silver nitrate application, copper cement and the atraumatic restorative technique have all had their proponents and proselytising disciples, and have all been discarded as serious ways to deal with decay in primary teeth; perhaps ozone treatment will go the same way. They have all promised so much and yet delivered so little.

If Dr Hall can persuade her patients, without local anaesthesia, to tolerate the discomfort of biting a PMC into place through a tight contact and into the gingival crevice, then surely she could persuade them to tolerate the discomfort of an injection. Where approximating carious molars have spontaneous marginal ridge breakdown, as is acknowledged in the paper, not only is there almost certainly irreversible pulpal involvement which will require pulp therapy, but there is also going to be loss of mesial-distal space. This spaceloss situation makes PMC fitting more difficult at the best of times, let alone without anaesthesia, and the resultant poorly-fitting buccal and lingual margins will lead to a chronic periodontal condition.

While it has been shown that a welladapted fissure sealant has the potential to arrest superficial carious lesions, this is not the case for deep dentinal caries where substrate is available from the pulp. What does the Hall Technique do to arrest caries? If the answer is that it doesn't, then should it be used, at the very least from an ethical standpoint?

We acknowledge the wide gulf between paediatric dental restorative techniques recommended by specialist bodies and that provided by GDPs, but the answer must not lie in unproven expediencies. The Hall technique, like the atraumatic restorative technique, perhaps has a place in the field, in developing countries. Elsewhere it should merit only a passing mention.
J. F. Roberts
N. Attari
London

1. Innes N P T, Stirrups D R, Evans D J P et al. A novel technique using preformed metal crowns for managing carious primary molars in general practice - a retrospective analysis. Br Dent J 2006; 200: $451-454$

\section{doi: 10.1038/sj.bdj.4813693}

\section{Adding to the debate}

Sir, I write having read Dr Mew's letter (BDJ 2006; 200: 360) titled Courage for debate in response to the series of letters in turn responding to his original opinion article Science versus empiricism (BDJ 2005; 199: 495-497).

Dr Mew writes that these responses 'tended to be personal rather than scientific'. I have no intention in becoming embroiled in arguing against the majority of the vitriolic statements within Dr Mew's most recent letter, most being irrelevant to his original thesis Science versus empiricism. Similarly, I have no wish to become involved in a 'plaster on the table' competition. It would be more appropriate if Dr Mew published his research in one of the peerreviewed dental or orthodontic journals. The dental profession could then analyse his results along with the other research on growth guidance.

Dr Mew mentions specifically in reply to my own letter that "negative evidence is dangerous'. Indeed this can be true such as the 'negative evidence' of the existence of weapons of mass destruction (WMDs) in Iraq in advance of the recent conflict.

However, Dr Mew will appreciate that orthodontic evidence is actually scrutinised before publication in peerreviewed journals by independent reviewers. That the four recent randomised controlled trials involving a total of 598 subjects have failed to confirm that growth modification appliances can guarantee an enhancement of skeletal growth in terms of either magnitude or direction ${ }^{1-4}$ is proof enough for the majority of the dental profession. It is just unfortunate that some clinicians continue to ignore the scientific evidence that so clearly indicates that functional appliances cannot enhance the magnitude or alter the direction of skeletal growth.

If Dr Mew has good quality growth guidance evidence to the contrary, then it should be published to add to the debate.

\section{G. T. McIntyre}

\section{Dundee}

1. Keeling S D, Wheeler T T, King G J et al. Anteroposterior skeletal and dental changes after early Class II treatment with bionators and headgear. Am J Orthod Dentofac Orthop 1998; 113: 40-50.
2. Ghafari J, Shofer FS, Jacobsson-Hunt U et al. Headgear versus function regulator in the early treatment of Class II, division 1 malocclusion: a randomized clinical trial. Am J Orthod Dentofac Orthop 1998: 113: 51-61.

3. Tulloch J F, Proffit W R, Phillips C. Outcomes in a 2-phase randomized clinical trial of early Class II treatment. Am J Orthod Dentofacial Orthop 2004; 125: 657-667

4. O'Brien K, Wright J, Conboy F et al. Effectiveness of early orthodontic treatment with the Twin-block appliance: a multicenter, randomized, controlled trial. Part 1: Dental and skeletal effects. Am J Orthod Dentofac Orthop 2003; 124 234-243.

doi: 10.1038/sj.bdj.4813694

\section{Sepsis audit}

Sir, we are writing in response to the letter published 11 March 2006 (An alarming increase in dental sepsis). We share the same concerns as Mr Carter and Mr Starr at Hull Royal Infirmary regarding the presentation of patients to Accident and Emergency departments with dental sepsis. There is indeed evidence that dental sepsis can result in death, but this is rare. There is no doubt, however, that it poses a significant impact on service provision and financial implications, both to the patient and National Health Service.

We have carried out a similar retrospective audit of numbers of patients presenting to oral and maxillofacial surgery services at Leeds General Infirmary with oro-facial and cervical sepsis of dental origin requiring admission for management.

Our data (see Table below) for the last six years did not reflect the same trend as that in Hull where a 47\% increase was observed from 1999 to 2004, the latter admittedly from smaller data numbers.

\begin{tabular}{|l|l|}
\hline Year & Patients admitted with dental sepsis \\
\hline 2000 & 80 \\
\hline 2001 & 58 \\
\hline 2002 & 40 \\
\hline 2003 & 46 \\
\hline 2004 & 50 \\
\hline 2005 & 64 \\
\hline
\end{tabular}

The picture is clearly more complex. The introduction of the new dental contracts in April 2006 and the potential changes in accessibility of dental services will alter the situation further, most likely a worsening of the problem. There is a case for a prospective national audit in this instance.

\section{G. Morris \\ T. K. Ong \\ Leeds}

doi: 10.1038/sj.bdj.4813695 